\title{
The Current Status and Challenges of the Human Resource Developments in Kosovo
}

\author{
PhD Cand. Naim Ismajli \\ European University of Tirana, Albania \\ Mobile: +377448448, Mail: naim.ismajli@rks-gov.net \\ Mr. Donat Rexha \\ European University of Tirana, Albania \\ Mail:donat.rexha@universitetiaab.com \\ Mr. Fidan Qerimi \\ European University of Tirana, Albania
}

\author{
Doi:10.5901/mjss.2013.v4n10p548
}

\begin{abstract}
The purpose of this article is to explore the status and challenges of human resources and development in Kosovo. Literature review suggested that government intervention, vocational and technical education, social network, and organizational structures are the key factors that influence human resources and development practices in the country. Beyond that the paper aims to compare the evaluation of performance in other sectors of well and then through comparison has a purpose to promote value-added production and skilled workforce in the organizations via developing various national labor enhancement policies, strategies and regulations and providing a set of training subsidies for employee in all sectors. Human resource development has become an essential component the development process. This is due to the fact that any development process is driven by the human factor. It is further urge, that policy formulation is a journey with challenges. The strength of the policy implementation lies in identifying such challenges, and finding ways of overcoming them. Lastly, the discussion reveals that human resource development is closely linked to other human resource factors that pertain at a given period, such as recruitment policies, labor market patterns, the age and experience of staff etc. Human resource development policies therefore must be reviewed from time to time to keep in step with the changing environment. It also highlights the key challenges faced, the lessons learnt and the way forward in enhancing sustainable human resource development in the country.
\end{abstract}

Keywords: Human resources, development, challenges, training, strategy, policy, management

\section{Introduction}

Kosovo's economy until the late 60s has been well developed. The economic development started in the 70 s and up to 80 years-it has been a good development, but political instability of recent years ' 80 and '90-tions made to the Kosovo economy gradually be destroyed and the economy verge happened in '98 and ' 99 war between Kosovo and Serbia. Therefore, current education sector in Republic of Kosovo is characterized by extensive reform efforts in all subsectors, addressing key challenges of increasing participation and improving equity and quality of education with limited resources. The last decade has seen a proliferation of new legislation, construction of schools and classrooms and setting up of new institutions. Human resource development has become an essential component the development process. This is due to the fact that any development process is driven by the human factor. It is further urge, that policy formulation is a journey with challenges. The strength of the policy implementation lies in identifying such challenges, and finding ways of overcoming them. Human resource development is closely linked to other human resource factors that pertain at a given period, such as recruitment policies, labor market patterns, the age and experience of staff etc. Human resource development policies therefore must be reviewed from time to time to keep in step with the changing environment. It also highlights the key challenges faced, the lessons learnt and the way forward in enhancing sustainable human resource development in the country.

Based on the theory and the information that will collect in Kosovo's companies will give recommendations on how 
the human resources should be treated, what methods and what tools to use companies to develop human resources. As noted in the introduction to this paper that Human Resources are the source that give life organization, is therefore the most important resources in the organization and handling of human resources will need to be special.In this study we will use quantitative and qualitative method. Quantitative method we will conduct survey to collect data from different organizations and institutions for human resources and development, and collect data from the staff that are treated as human resources. The main objective of this study is to explore the status and challenges of human resources and development in Kosovo.

\section{Research Methodology}

The research will be conducted by collecting data from available primary and secondary sources such as survays, statutes, cases, books, encyclopedia, journals, seminar, conference papers and internet materials. A survay has beeen conducted with the staff of the differnet organizations and instituions in Kosovo. The aim of this survay is to assess and collect data on the HR development, performance and challenges faced by organizations and institutions in Kosovo.

\subsection{Objectives}

The main purpose of this study is to explore the status and challenges of human resources and development in Kosovo. Literature review suggested that government intervention, vocational and technical education, social network, and organizational structures are the key factors that influence human resources and development practices in the country. To understand the current status of HR development in Kosovo by identifying;

- $\quad$ key HR development aspects of interest

- the membership status and how HR Association could contribute further

- $\quad$ strengths and weaknesses of HR professionals

- HR challenges faced by organizations

\subsection{Key HR development aspects of interest in Kosovo}

The majorities of professional and administrative staff working in independent institutions are civil servants, and are paid according to the relevant legislation in place. In most organizations, there is a person covering HR but who cover it varies as: owner/manager, HR Profesionals, accounting and administrativ positions. The HR development is mainly focused on the following HR aspects: recrutment, learning and development, personal administration and remunartion and benefits. Most of the organizaions in Kosovo do not have proper process of the HR aspects. Only few organizatons have saperate department for HR, which tells us that HR is still in begining process of development. According to one survey, one-fourth of independent institutions have one or more senior positions where the incumbent's mandate has expired. In fact, there have been numerous cases when the appointment procedure took more than one year, which severely hampered the work of these organizations. "The State of Independent Institutions in Kosovo". For example, the recruitment of the first local Ombudsperson had taken four years, with the process finally concluded in 2009. The subsequent recruitment of the five Deputy ombudspersons took place between 2010 and 2011 and lasted more than one year. The recruitment of the IMC Council has also encountered serious delays. The mandate of all the board members has expired, with three of them vacant for more than one year. As a result, the IMC Council has been unable to make any decision over the past year due to the lack of quorum as its board membership was decimated by mandate expiry. (July 2012 Organization for Security and Co-operation in Europe, "The State of Independent Institutions in Kosovo", July 2008. http://kalyancity.blogspot.com/2011/04/what-is-management-definitions-meaning.html). The reasons for these delays include the poor advance planning for upcoming vacancies and a lack of suitable candidates once the appointment procedure commences. Therefore, there is need and inters for developing the HR aspects in most of the big organizations in Kosovo. The weakness of HR professionals in Kosovo according to the survey that we have done are:

\subsubsection{Lack of professional experience}

As we know that Kosovo is a new independent country, with only 5 years of independence, so by far we had a lot of problems in front of us. Due to this we couldn't advance our professional background as a country, as well as in the HR area we had obstacles. We didn't have any professional experience on HR, this was sort of new for us, so we had a lot to 
do in this case.

\subsubsection{Lack of qualification}

Also, qualification was another issue of us. Our universities, nor public nor private didn't offer programs on HR, so we didn't actually have a clue. The only source for HR qualified people were from those who studied abroad, even though most of them didn't come back to their home country, causing that brain drain effect, which was destroying us as a country.

\subsubsection{Low level of business sector awareness}

As we mentioned previously Kosovo had a lot of problems on professional experience and qualification. So, these lacks rewarded us with a low level of business sector awareness, where unqualified people opened companies and small businesses, so they weren't aware of HR area, and how important is it for the good of a company or business. So, due to this we had unsatisfied employees, with no rights, whom were obliged to work, because they needed money.

\subsubsection{Low level of problems awareness}

In this internet world, is impossible to not know about the new approaches on professional field. Also, we can see about this HR thing, read more about it and get familiar with. But, the problem is that we close our eyes to this new approaches and go on with the old. This is the issue on problems awareness. We ( business sector) only make the money flow, and don't care about the workers, who liked or not they have to work. So, this is the issue in Kosovo, we see things, but we close our eyes when it comes to implement them in our businesses. The major HR challenges in Kosovo organizations can be foressen as below:

\subsection{Changing culture}

This passing years, and also after the independence we were opened to new things that were coming to us. One of those were organizations and businesses from abroad. They brought within also a new culture, which was a bit hard for us to adapt. This also caused our HR not so productive in this field.

\subsection{Motivation}

Kosovars are known as very optimistic people, and also as hard workers. But, as everyone we need motivation to do a better job. And we can say that we lack of motivation. We don't have enough creativity, new ideas, aggregators that would motivate employees to do a better job and also be more creative by themselves.

\subsection{Recruiting professionals}

If we want to be better on the future, for sure we have to see where problems are and fix them. We had a chance to know about qualifications, professional experience and other lacks on our way. So, we have to recruit professionals, as national ones, also from abroad that would learn us and expand the knowledge about HR importance. ${ }^{1}$

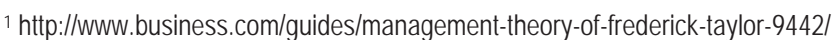

${ }^{1}$ Baki Koleci, Fetah Reçica \& Neritan Turkeshi; Menaxhment; fq 28, Universiteti AAB
} 


\subsection{Results for the survay}

\section{Graph. 1.}

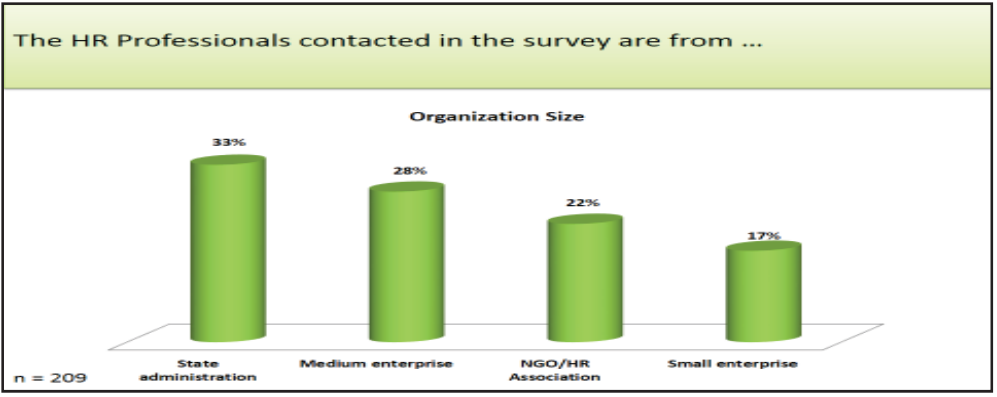

The chart shows that of 209 respondents $33 \%$ are run by state organizations directly or indirectly, $28 \%$ of medium businesses, NGOs and $22 \%$ of small businesses by $17 \%$. From this we see that small businesses have a low level of knowledge of HR and HR do not pay attention.

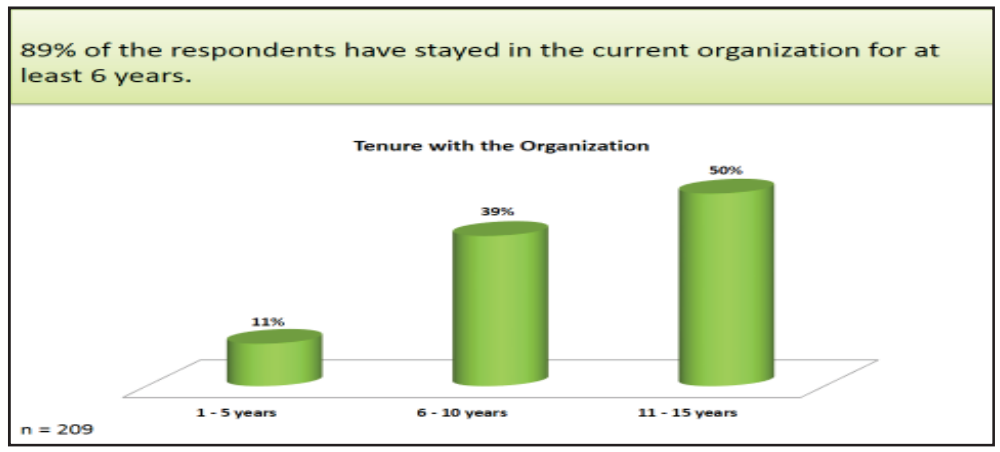

Graph. 2.

When we asked how long they have been working at the same company, answered by 209 respondents only $11 \%$ in alternative 1-5 years, 6-10 years 39\% and 50\% 11-15 years, these answers do not understand that in Kosovo have a permanent workers, ie a worker employed in a company and the company does not change. Here you have two means of assessing, on the one hand we have a no movement of workers, which makes employees feel that they have different experiences, which remain less skilled and less flexible in performing, but on the other hand if the value of the company is positive because if companies invest in these human resources are sure will not lose after a while.

\section{Graph. 3.}

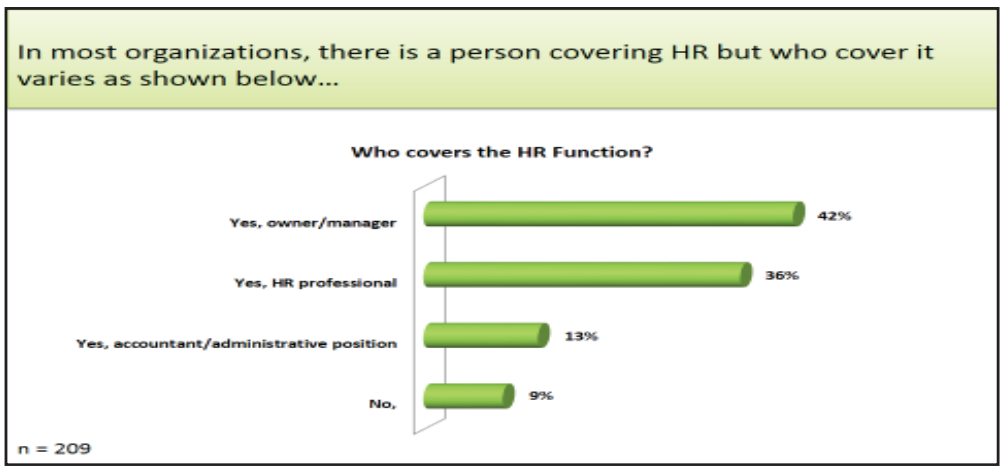


From answered that we get $42 \%$ see the owner or manager who deals with human resources, accountant handles $13 \%$, $9 \%$ have not taken one and 36\% have a professional HR expert, ie by $64 \%$ in our survey Kosovo, HR is not treated professionally, only 36 have professional workers who deal with HR.

\section{Graph.4.}

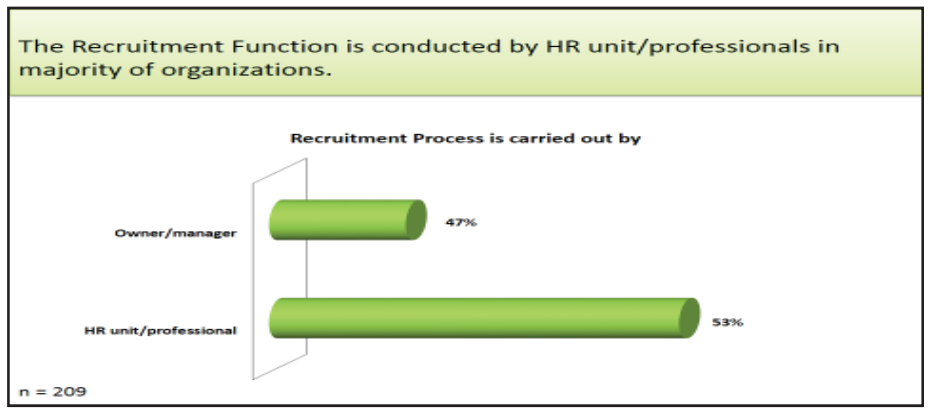

From this we see that the recruitment function becomes $47 \%$ of owners and managers and $53 \%$ of the unit's HR professional. Also see these responses have yet to be desired in this respect as this feature still be owners or managers and not allowed to work professional people who are trained in this field.

\section{Graph.5.}

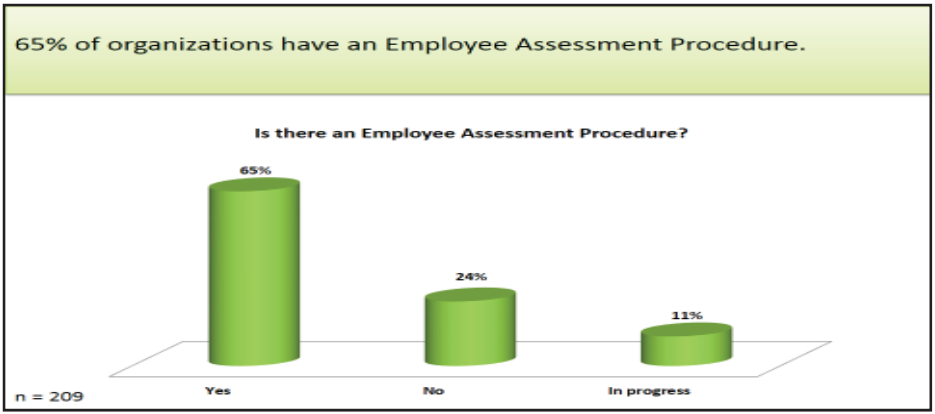

On the question whether an employee evaluation procedures in organizations have received positive responses $65 \%$ and $11 \%$ are in progress processing of employee evaluation procedure. From this we see that progress in the evaluation of employees, since companies are developing procedures for evaluating its employees.

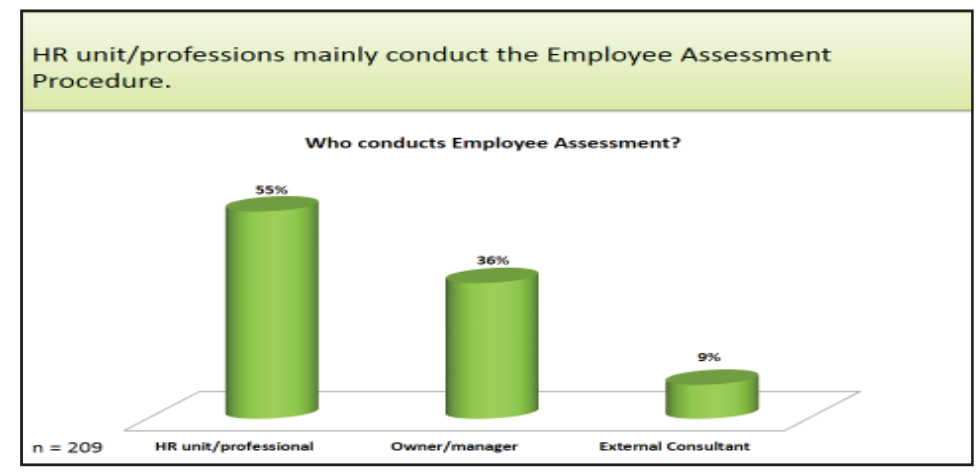

Graph.6. 
Question of who performs the evaluation of employees responded to the HR department and $55 \%$ to $9 \%$, external consultants and $36 \%$ have taken owners and managers. Also in this regard, we see an improvement in relation to the first question, which dealt with who deal with HR.

\section{Graph.7.}

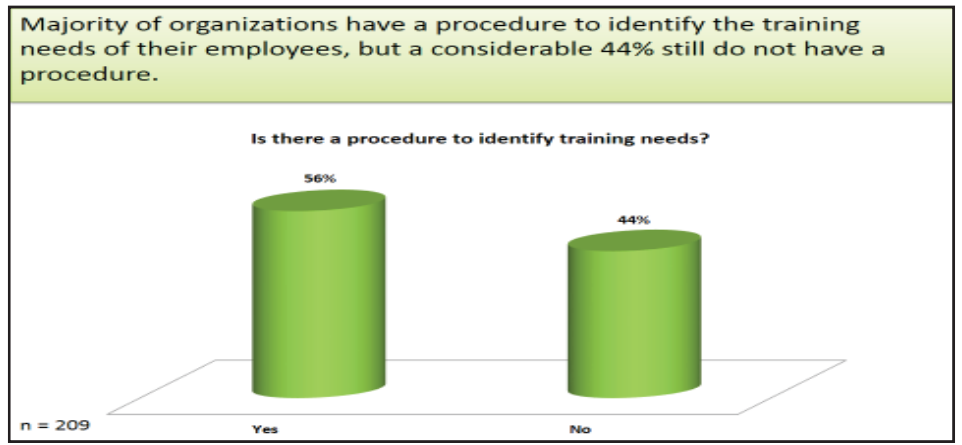

Wanting to identify on the identification of training needs of employees, our question whether the identification procedure of training $56 \%$ responded that the identification procedures for training and $44 \%$ answered NO.

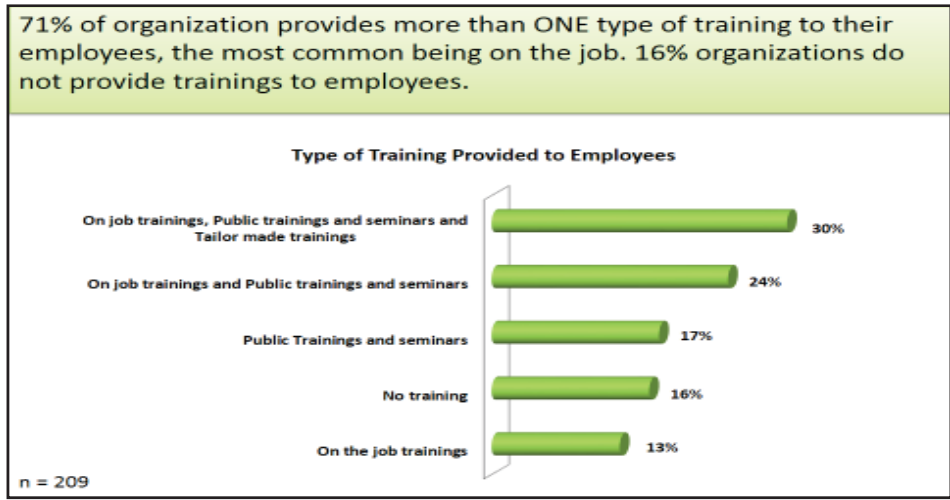

\section{Graph.8.}

The chart shows that $71 \%$ of organizations hold more than one training for their employees, $16 \%$ of organizations do not keep training at all and $13 \%$ of organizations only keep the job training.

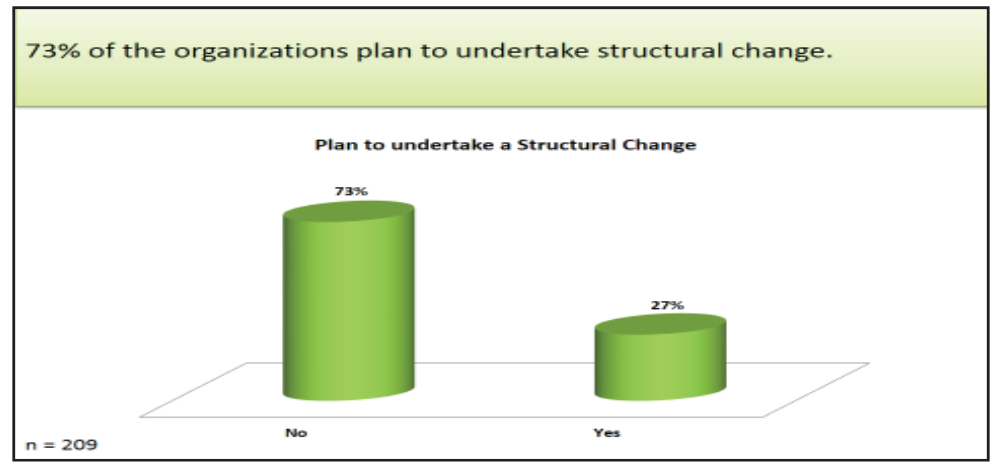

\section{Graph.9.}


Asked about the changes in structure, have $73 \%$ have a negative response signal that these companies have not yet realized that there must be changes in the treatment of HR to achieve success in the market.

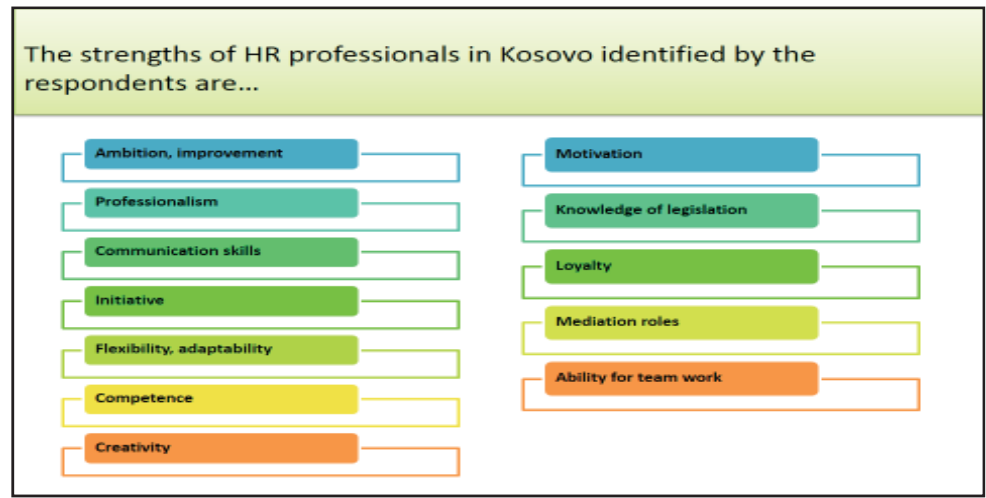

\section{Graph.10.}

The priorities identified by respondents to the professionalism of HR are: Ambition and improvement, professionalism, communication skills, flexibility and adoptiviteti, competence, creativity, motivation, recognition of the legislature, loyalty, and mediation role attribute for team work.

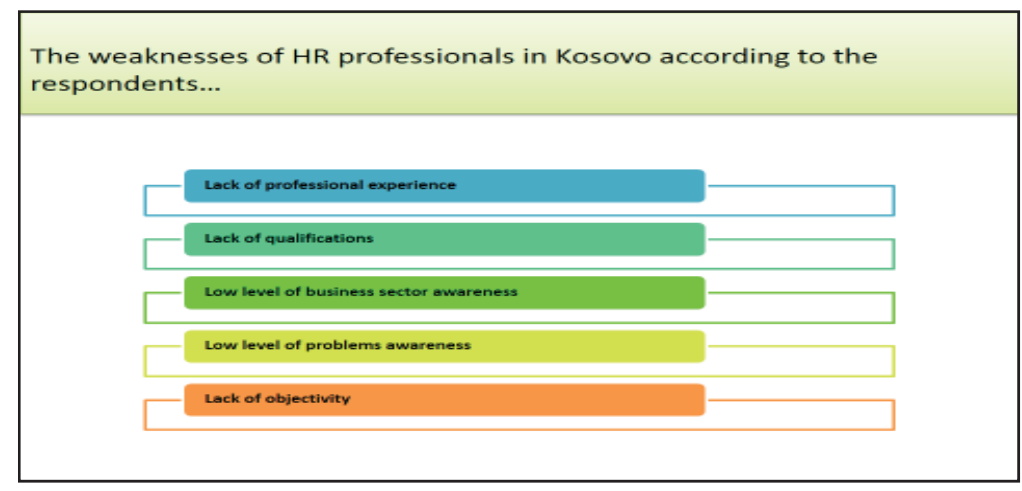

\section{Graph.11.}

According to the research we draw these vulnerabilities for HR: Lack of professional experience, lack of qualifications, low level of awareness, lack of targets.

\section{Graph.12.}

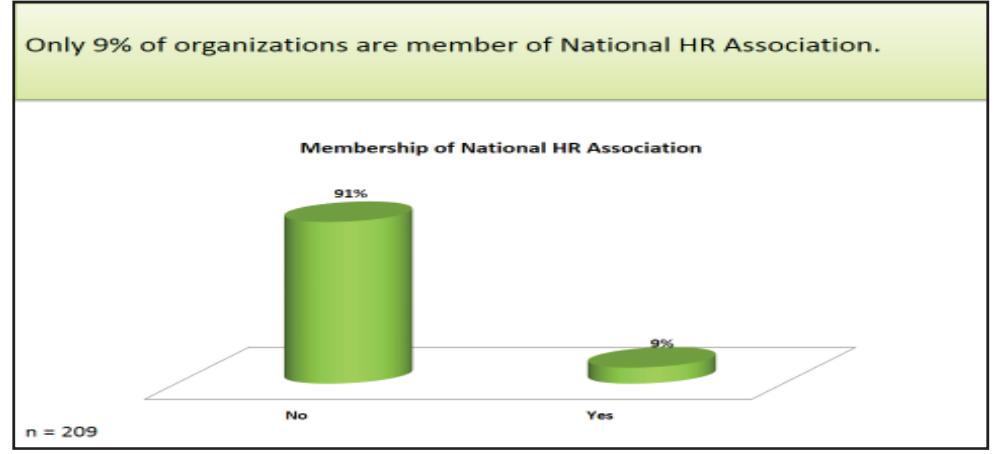


On the question of whether you are part of an association of HR have a negative $91 \%$ and $9 \%$ positive response. From this we see that organizations generally do not deal with human resources, the source that gives life to a company that is the source without which all the company would not have a value.

\section{Conclusions / Recomandations}

Based on the study and survey that we have done we can argue that HR status in Kosovo is still in development process and there is a lot of need for improvements and changes. So, in order to improve human resources in Kosovo there is a need for new training modules and practices where employed can be trained and updated with new knowledge and be more productive. Another thing that needs to be done is to reform the education system, this can help employees to gain more knowledge regarding the needs of the market and at the same time organizations will find easier to select and make decision for the right employees. Training abroad is also one thing that needs to be done and can help a lot to these companies that operate outside Kosovo because as we mentioned above after the independence we were opened to new things that were coming to us. One of those were organizations and businesses from abroad. They brought within also a new culture, which was a bit hard for us to adapt. This also caused our HR not so productive in this field. At the end we need also to have a naw information sources such as professional studies, periodical issues, internet forums in order to help organizations to have proper process of the HR development aspects.

\section{References}

The Role of Human Resource Development and Management, http://www2.aau.org/wghe/gender/toolkit/Toolkit-module3.pdf Stephen P Robbins \& Mary Coulter MANAGEMENT (11th edition.)Prentice Hall (ISBN 978-0-13-216384-2)

Paul Banfield \& Rebecca Kay, Introduction to human resource management, Oxford Universitety Press (ISBN: 978-99956-39-43-3)

Claude Balthazard, Ph.D., C.H.R.P.\&Susan Robinson, The Role and Future of HR: The CEO's Perspective, Human Resources Professionals Association.

Continuity and Change: The Role of the HR Function in the Modern Public Sector

Ashly Pinnington, Rob Macklin and Tom Campbell, Human Resource Management - Ethics and Employment, Oxford Universitety Press (ISBN: 978-0-19-920378-9)

Michael Armstrong, Human Resource Management Practice, 10th Edition, Kogan Page London and Philadelphia

Alharthey, Bandar Khalaf* and Amran Rasli, Key role of strategic human resource management (SHRM) in advancing the degree of team learning, Gusht 2011

Derek Torrington, Laura Hall \& Stephen Taylor, Human Resource Managment, 6th Editon, Prentice Hall, (ISBN: 027368713 1)

Standarde pwr administrim me resurse njerwzore, Shtatorw 2009,(ISBN: 978-9989-182-25-9)

Jeffrey A. Mello, Strategic Human Resource Management, 2nd Edition, Towson University, 2006, (ISBN: 0-324-29043-8)

Coro Strandberg,May 2009, The role of human resource management in corporate social responsibility, Strandberg Consulting,

A New Role For Management In Today's Post-Industrial Organization by Mitch McCrimmon Leadership | July / August 2010 http://www.iveybusinessjournal.com/topics/leadership/a-new-role-for-management-in-today\%E2\%80\%99s-post-industrialorganization\#.UVLyPRfV-Sp 